\title{
Stimuli-Responsive DNA Binding by Synthetic Systems
}

Jessica Rodriguez, Jesuś Mosquera, Soraya Learte-Aymamí, M. Eugenio Vaźquez, José Luis Mascareñas

\section{Peer reviewed version}

This is the peer reviewed version of the following article: Rodriguez, J.; Mosquera, J.; Learte-Aymamí, S.; Vaźquez, M. E.; Mascareñas, J. L. (2020), Stimuli-Responsive DNA Binding by Synthetic Systems. Acc. Chem. Res., 53: 2286-2298, which has been published in final form at https://doi.org/10.1021/acs.accounts.0c00415. This article may be used for non-commercial purposes in accordance with ACS Terms and Conditions for Use of Self-Archived Versions.

\section{How to cite:}

Rodriguez, J.; Mosquera, J.; Learte-Aymamí, S.; Vaźquez, M. E.; Mascareñas, J. L. (2020), Stimuli-Responsive DNA Binding by Synthetic Systems. Acc. Chem. Res., 53: 2286-2298. doi: 10.1021/acs.accounts.0c00415

\section{Copyright information:}

(C) 2020 ACS. This article may be used for non-commercial purposes in accordance with ACS Terms and Conditions for Use of Self-Archived Versions 


\title{
Stimuli-responsive DNA binding by synthetic systems
}

\author{
Jessica Rodriguez, ${ }^{*, \perp}$ Jesús Mosquera, ${ }^{\dagger}$ Soraya Learte-Aymamí, $\perp$ M. Eugenio Vázquez, ${ }^{\perp}$ José Luis

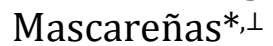

${ }^{\perp}$ Centro Singular de Investigación en Química Biolóxica e Materiais Moleculares (CiQUS), and Departamento de Química Orgánica. Universidade de Santiago de Compostela, 15782 Santiago de Compostela, Spain.

†Department of Pure and Applied Chemistry, University of Strathclyde, Glasgow, UK.

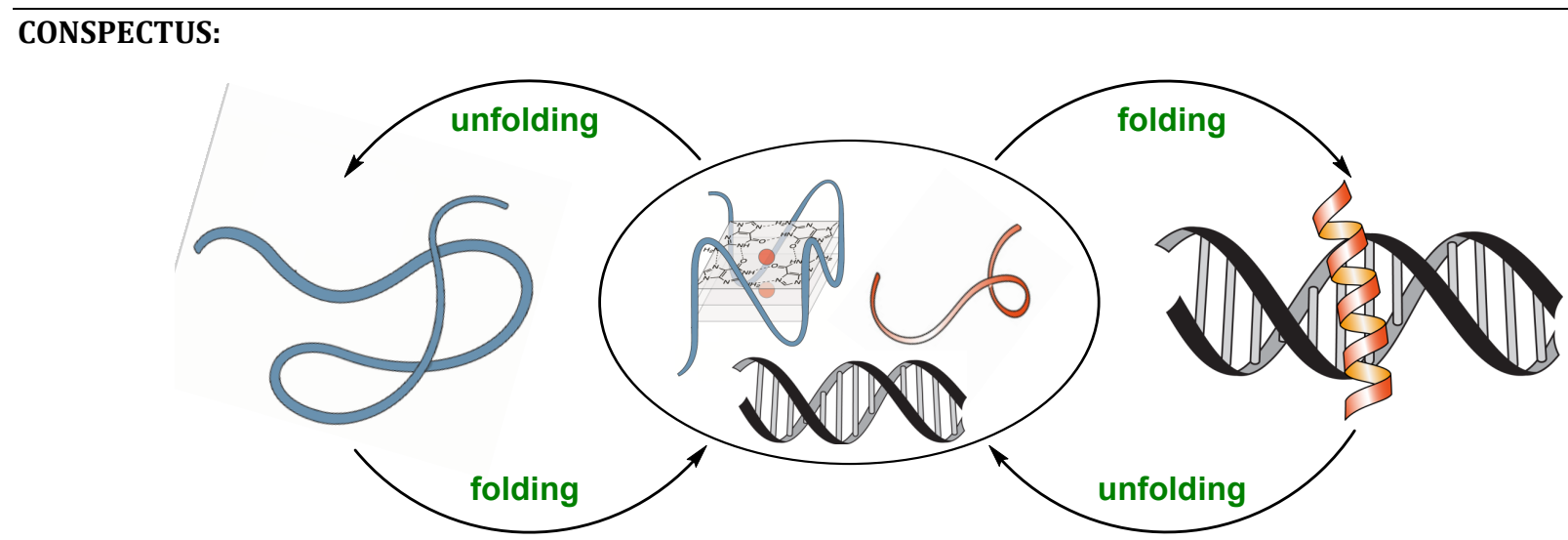

The DNA is the molecule responsible for the storage and transmission of the genetic information in living organisms. The expression of this information is highly regulated. In eukaryotes, it is achieved mainly at the transcription level thanks to specialized proteins called Transcription Factors (TFs) that recognize specific DNA sequences, thereby promoting or inhibiting the transcription of particular genes. In many cases, TFs are present in the cell in an inactive form but become active in response to an external signal, which might modify their localization, DNA binding properties, or modulate their interactions with the rest of the transcriptional machinery. As a result of the crucial role of TFs, the design of synthetic peptides or miniproteins that can emulate their DNA binding properties, and eventually respond to external stimuli is of obvious interest. On the other hand, although the B-form double helix is the most common DNA secondary structure, it is not the only with an essential biological function. Guanine quadruplexes (GQs) have received considerable attention due to their critical role in the regulation of gene expression, which is usually associated with a change in the GQ conformation. Thus, the development of GQ probes whose properties can be controlled using external signals is also of significant relevance.

In this Account, we present a summary of the recent efforts towards the development of stimuli-responsive synthetic DNA binders with a particular emphasis on our own contributions. We first introduce the structure of B and GQ DNAs, and some of the main factors underlying their selective recognition. We then discuss some of the different approaches used for the design of stimulus-mediated DNA binders. We have organized our discussion according to whether the interaction takes place with duplex or guanine quadruplex DNAs, and each section is divided in terms of the nature of the stimulus (i.e., physical or chemical). Regarding physical stimuli, light (through the incorporation of photolabile protecting groups or photoisomerizable agents) is the most common input for the activation/deactivation of DNA binding events. With respect to chemical signals, the use of metals (through the incorporation of metal-coordinating groups in the DNA binding agent) has allowed the development of a wide range of stimuli-responsive DNA binders. More recently, redox-based systems have also been used to control DNA interactions.

This Account ends with a "Conclusions and Outlook" section highlighting some of the general lessons that have been learned, and future directions towards further advancing the field.

\section{KEY REFERENCES}

- Jiménez-Balsa, A.; Pazos, E.; Martínez-Albardonedo, B.; Mascareñas, J. L.; Vázquez, M. E. Temporary electrostatic impairment of DNA recognition: light-driven DNA binding of peptide dimers. Angew. Chem. Int. Ed. 2012, 51, 8825-8829.1 Attachment of oligoglutamate tails to a GCN4-based peptide through a photolabile linker effectively inhibits its DNA binding ability. Upon UV light irra- diation, the polyanionic chain is released and the DNA interaction restored.

- Sánchez, M. I.; Mosquera, J.; Vázquez, M. E.; Mascareñas, J. L. Reversible supramolecular assembly at specific DNA sites: nickel-promoted bivalent DNA binding with designed peptide and bipyridyl-bis(benzamidine) components. Angew. Chem. Int. Ed. 2014, 53, 9917-9921. ${ }^{2} \mathrm{Ni}^{2+}$ salts promote the selective bivalent recognition of a designed DNA sequence. The strategy involves the reversible 
nickel-promoted assembly of a bis(histidine)-modified GCN4 peptide and a bis(benzamidine) unit modified with a bipyridine ligand.

- Rodríguez, J.; Mosquera, J.; Couceiro, J. R.; Vázquez, M. E.; Mascareñas, J. L. Ruthenation of non-stacked guanines in DNA G-quadruplex structures: enhancement of c-MYC expression. Angew. Chem. Int. Ed. 2016, 55, 15615-15618. ${ }^{3}$ Bulky ruthenium complexes featuring photolabile thioether ligands selectively metalate sterically accessible guanines in the c-myc GQ after irradiation with visible light. This ruthenation promotes a substancial enhancement in the transcription of this oncogene.

- Learte-Aymamí, S.; Curado, N.; Rodríguez, J.; Vázquez, M. E.; Mascareñas, J. L. Metal-dependent DNA recognition and cell internalization of designed, basic peptides. J. Am. Chem. Soc. 2017, 139, 16188-16193.4 A monomeric bis(histidine)-modified GCN4 peptide binds to its consensus target DNA site with high affinity and selectivity upon addition of $\mathrm{Pd}(\mathrm{en}) \mathrm{Cl}_{2}$. Furthermore, this metal-mediated stapling triggers an efficient cell uptake of this peptide.

\section{INTRODUCTION}

DNA is a biopolymer formed by deoxyribonucleotide units. The most stable structure of DNA is formed when the two complementary chains get together as an antiparallel dimer. Such dimeric structures are found under physiological conditions in the so-called "B" form of the DNA, which is the famous right-handed double helix. ${ }^{5}$ The geometry and chirality of the sugars leads to the formation of two grooves in a right-handed helix, known as the major and minor grooves, which exhibit different sizes and geometric attributes (Figure 1a). The major groove is relatively wide and shallow, while the minor groove is narrow and deep.

Importantly, the major groove presents a more diverse pattern of hydrogen bond donors and acceptors than the minor groove (Figure 1b), and therefore offers more possibilities for distinguishing recognition partners. ${ }^{6}$ This higher information density, together with its greater accessibility, is the reason why, in most protein-DNA complexes, sequence specificity is determined by protein-DNA interactions that take place in the major groove. Conversely, the narrow minor groove favors the interaction with planar molecules and can only accommodate peptides in extended conformations.

While the B-DNA double helix is the predominant form in biological media, other secondary structures are also possible. One of the most relevant family of non-canonical secondary structures are the G-quadruplexes (GQs), which are particularly prominent in telomeres and gene promoters, and play key cellular regulatory roles. ${ }^{7} \mathrm{GQs}$ consist of two or more guanine tetrads folded into a compact arrangement through Hoogsteen hydrogen bonds (Figure 2, top). The $\pi$-stacked guanine tetrads in GQs are connected by sequences of variable length that form different loops. In contrast to the standard B-form of double-stranded DNA (dsDNA), GQs show a wide diversity of topologies, depending on the number and length of the guanine tracts, their relative orientation, and the nature of the intervening loop regions (Figure 2, bottom). ${ }^{8}$ The recognition of GQs has been mainly achieved by using planar aromatic systems, which stack on top of the guanine tetrads forming $\pi-\pi$ interactions that also stabilize the GQ. ${ }^{9}$
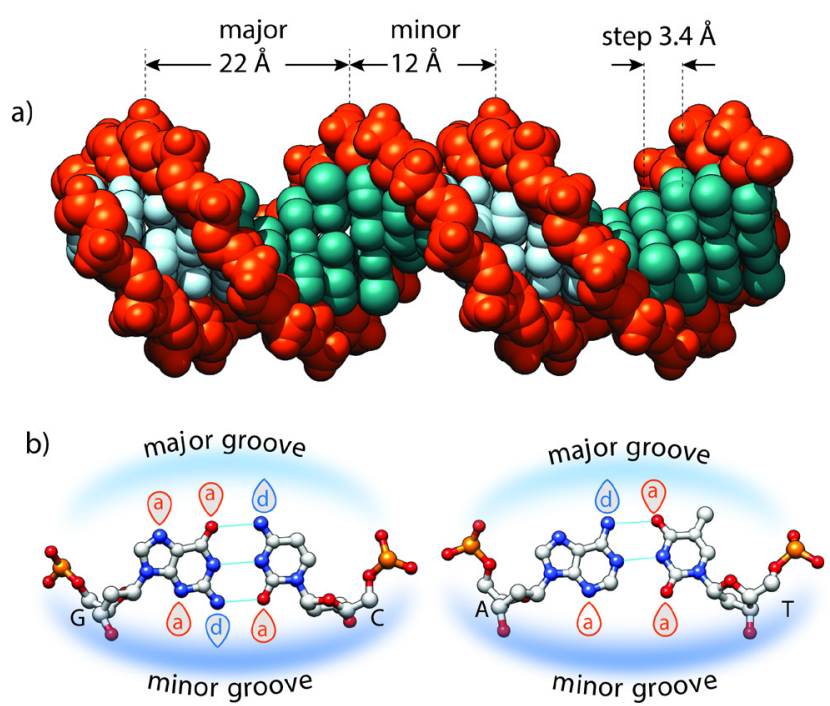

Figure 1. a) Idealized B-DNA indicating the main geometric features. b) $A / T$ and $G / C$ base pairing in DNA indicating the hydrogen bond donors and acceptors.

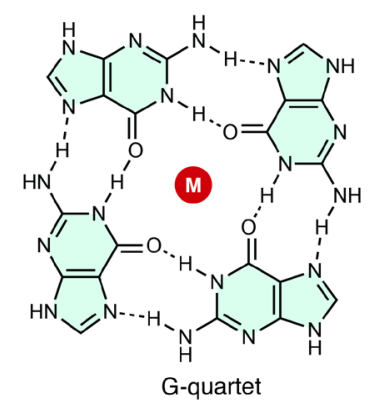
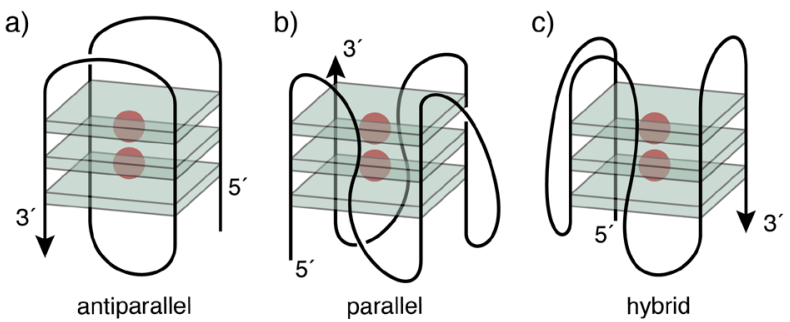

Figure 2. Top: Chemical structure of a guanine tetrad in a GQ. $\mathrm{M}^{+}$represents a monovalent cation (typically $\mathrm{K}^{+}$or $\mathrm{Na}^{+}$). Bottom: Representative examples of the topology polymorphism in DNA GQs.

\section{STIMULI-RESPONSIVE BINDING TO dsDNA}

\section{1 dsDNA BINDING BY SYNTHETIC PEPTIDES}

Gene expression is mainly controlled by the action of TFs, 10 which can be classified into families according to the structure of their DNA binding domain. One of the most important family of TFs is the basic leucine zipper (bZIP). bZIP proteins bind their consensus DNA sequences as non-covalent homo- or heterodimers of uninterrupted $\alpha$-helices. Each helix presents two different regions: the basic region and the leucine zipper (Figure 3, top). ${ }^{11}$ The N-terminal basic region directly interacts with the major groove of the DNA and the C-terminal leucine zipper region is required for the dimerization of the two DNA binding regions. An important consideration about 
the bZIP-DNA proteins is that they are intrinsically disordered in the absence of their target DNA, so that their folding is coupled to the DNA recognition process. ${ }^{12}$ Therefore, the DNA binding event entails an entropic cost associated with the folding of the peptide chain that cannot be compensated by the enthalpic gain resulting from the binding of a single monomer. In consequence, they need to dimerize to form DNA complexes. One of the better characterized bZIP proteins is GCN4, a yeast transcriptional activator that specifically binds the palindromic sequence ATF/CREB (5'-ATGAcgTCAT-3') and the pseudopalindromic sequence AP-1 (5'-ATGAcTCAT-3') as a homodimer.13

Owing to their structural simplicity, bZIP TFs have been chosen many times as the starting point for the design of minimized versions of TFs. ${ }^{14,15}$ In 1990, the group of Kim reported that the leucine zipper region of GCN4 could be replaced by a disulfide bond to dimerize short GCN4 basic regions (br) without significantly affecting the DNA binding properties of the resulting minimized construct (Figure 3a). ${ }^{16}$ Following this pioneering work that demonstrated the modular nature of the bZIP TFs, several research groups described various linkers to dimerize the GCN4 basic regions to yield simplified DNA binders (Figure 3b-d).17,18,19
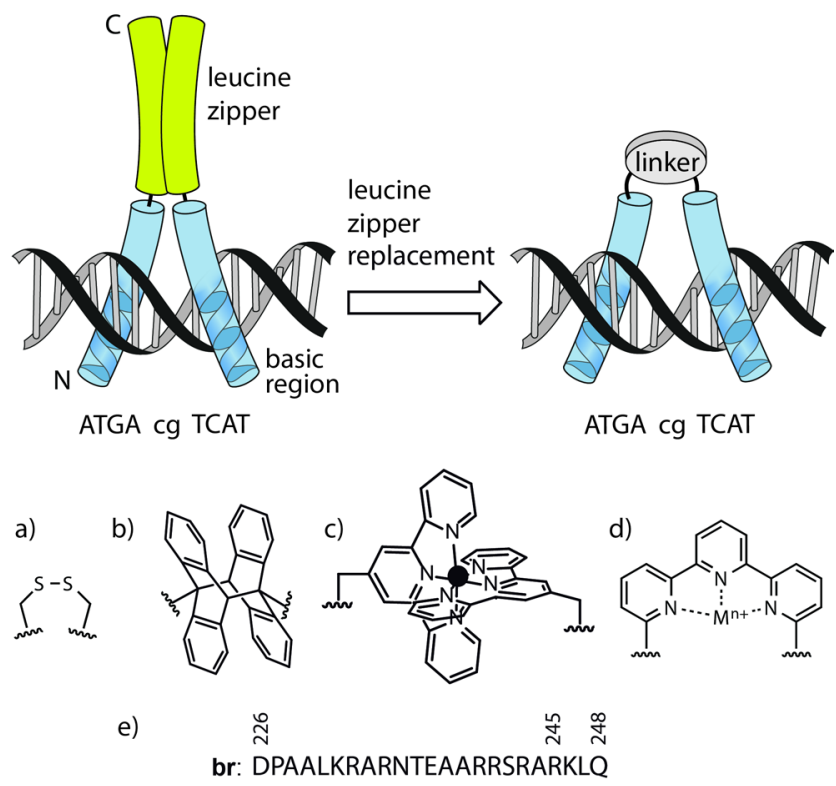

Figure 3. Top: Schematic illustration of the GCN4 bZIP DNA binding domain dimer, highlighting in yellow the leucine zipper and in blue the basic region; and replacement of the leucine zipper with synthetic linkers. Bottom: a) Kim's disulfide dimer. b) Peacock's photocontrolled anthracene dimer. c) Schepartz's $\mathrm{Fe}^{2+}$ complex as dimerizer. d) Peacock's metal switch. e) Sequence of the peptide identified as the minimum fragment of the natural GCN4 basic region (br) that, upon dimerization, displays the DNA binding properties of the full protein.

Our group has demonstrated that the DNA binding of an isolated basic region of a bZIP protein can be restored by appropriate covalent conjugation to minor groove DNA binders, such as bisbenzamidine, ${ }^{20}$ or AT-hook derivatives (Figure 4). ${ }^{21}$ These units act as anchors that, upon binding to its target sequence in the DNA minor groove, deliver the bZIP basic region into the adjacent major groove consensus site. Therefore, the resulting hybrids recognize with high affinity and selectivity a composite DNA sequence containing the peptide and the minor groove binding regions in adjacent sites. ${ }^{22,23}$ This strategy has been extended to other families of TFs, namely homeodomains (HTH) ${ }^{24}$ and zinc fingers (ZF). ${ }^{25}$
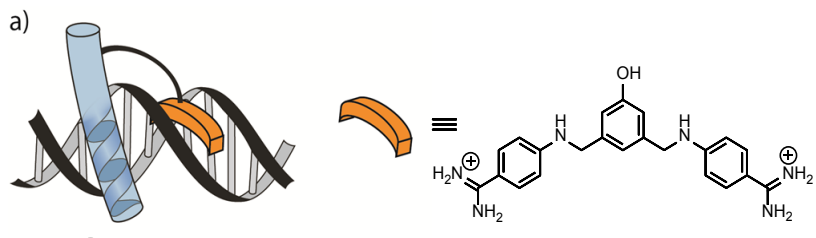

TCAT A ATT
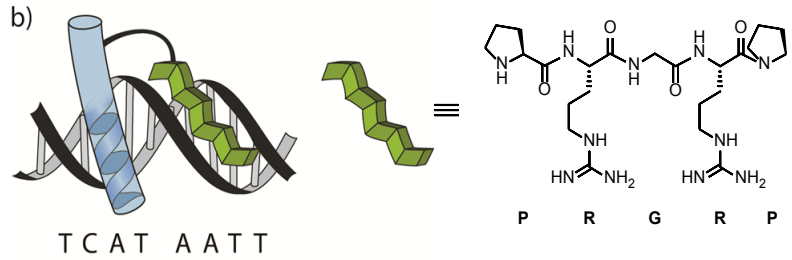

Figure 4. Schematic illustration of the simultaneous interaction of the GCN4 basic region and different minor groove binders in adjacent DNA sites. a) bisbenzamidine. b) AT-hook.

\subsection{LIGHT-MEDIATED dsDNA BINDING}

Light is an ideal input for the external regulation of molecular processes, including DNA recognition events. Light irradiation is non-invasive, and the use of long wavelengths is compatible with biological settings. The two approaches used for controlling DNA binding with light are photolabile caging groups and photoisomerizable units.

\section{Photolabile protecting groups}

Photolabile protecting groups can be used to inactivate the biological activity of a selected molecule by blocking a key functional group required for its function. When desired, the activity can be restored by irradiation and photorelease of the parent, unprotected biomolecule. This represents an excellent strategy for the spatiotemporal control of biological activity, ${ }^{26}$ and has also been used for regulating DNA interaction processes.

In 2012, we demonstrated that it is possible to inhibit the DNA binding of a dimeric GCN4 basic region by attaching short oligoglutamate tails at the $\mathrm{N}$-terminal end of a synthetic basic region peptide (br). ${ }^{1}$ Such negatively charged appendages generate an electrostatic repulsion with the polyanionic DNA backbone, thereby hampering the DNA binding (Figure 5a). To achieve stimulus-responsive binding, the polyanionic chains were connected to the br peptide through an orthonitrobenzyl (ANP) photolabile group, so that when the caged dimeric peptide is irradiated with UV light, the linker is cleaved, thereby releasing the negatively charged tails and irreversible restoring the peptide/DNA interaction.

We also implemented a strategy to deactivate the DNA binding upon irradiation. It is based on the use of a biselectrophilic $\mathrm{Ru}^{+2}$ bipyridyl complex as dimerizing linker to connect two GCN4 basic regions. ${ }^{27}$ As expected, the resulting dimer interacted selectively with its consensus DNA (Figure 5b). This $\mathrm{Ru}^{+2}$ complex can act as a photo-cleavable unit after visible-light irradiation. Therefore, irradiation of the dimer led to the disassembly of the peptide dimer and the consequent suppression of the DNA interaction. 
a)
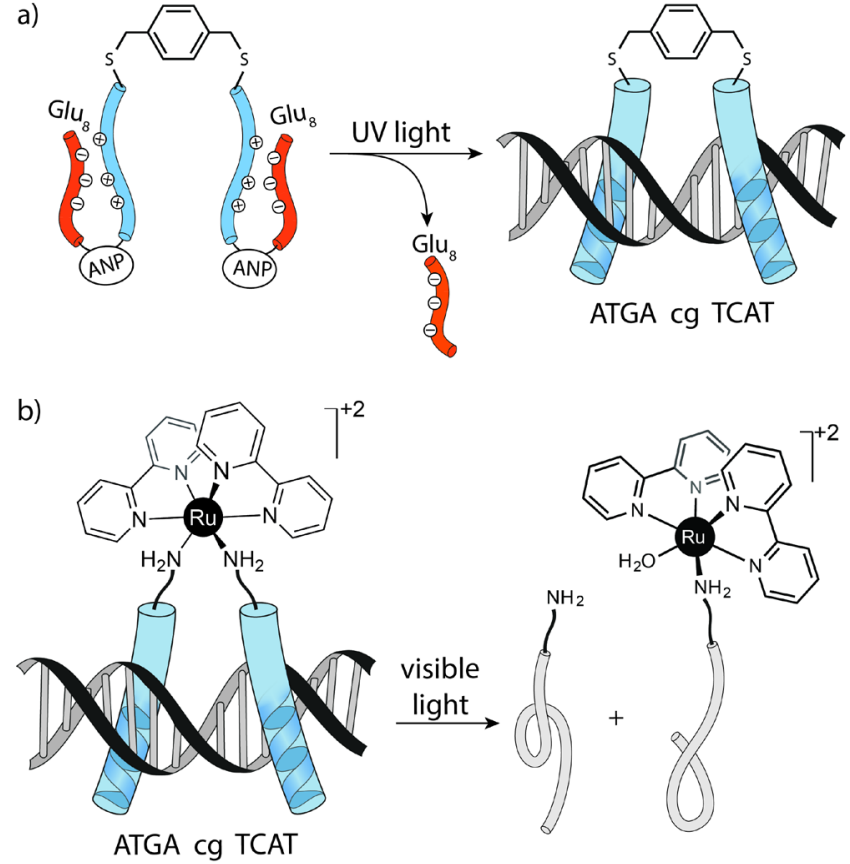

Figure 5. a) Schematic illustration for the electrostatic caging of two GCN4 basic regions and the light-mediated uncaging, and ensuing DNA binding. b) Representation of the photocleavable $\mathrm{Ru}^{+2}$ GCN4 dimer and light-mediated photouncaging with suppression of the DNA interaction.

Our group has also used photouncaging approaches to trigger DNA cleavage events, ${ }^{28}$ or the DNA insertion of minor groove binding agents. ${ }^{29}$ To this end, the amidinium groups of azapentamidine and DAPI were protected with the Nvoc (4,5dimethoxy-2-nitrobenzyloxycarbonyl) photolabile group. ${ }^{30}$ This modification precludes protonation and thus suppresses the electrostatic contacts with the DNA (Figure 6). The caged compounds are not able to bind DNA but, upon irradiation and consequent cleavage of the Nvoc protecting groups, the binding is restored.

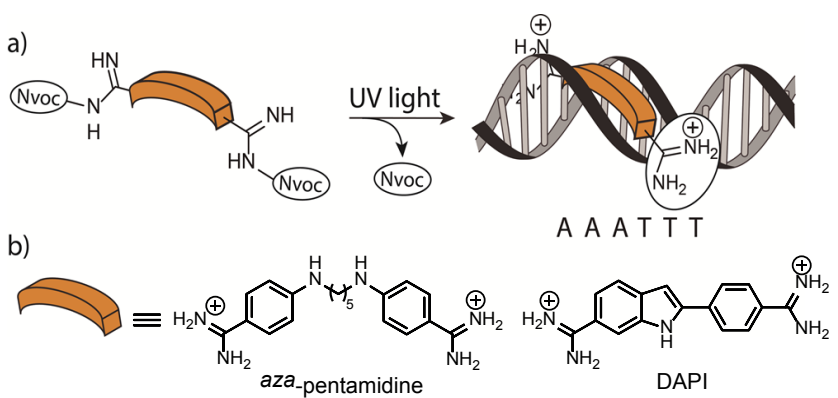

Figure 6. a) Representation of the light-promoted DNA binding. b) Structure of minor groove binders used.

UV irradiation has also been applied to drive DNA metalation events with transition metal complexes. ${ }^{31}$ This required the preparation of $\mathrm{Ru}(\mathrm{II})$ or $\mathrm{Pt}(\mathrm{II})$ complexes containing photolabile ligands in their coordination sphere, which are inert towards nucleophilic guanines in the DNA. However, upon irradiation, these ligands are replaced by water, producing reactive species which irreversibly coordinate with the DNA, usually through reaction with the N7 of guanines (Figure 7).
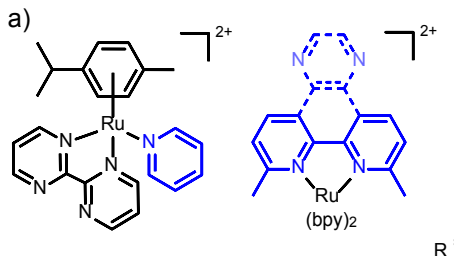<smiles>[R]C1=CC([R])=[PH](N[CH])O[P@]1(N)N[3H]</smiles>
$\mathrm{R}=$<smiles>CCC=Cc1ccc(O)c(O)c1</smiles>

b)<smiles>CCCC1(CC)CC(n2cnc3c(=O)[nH]c(N)nc32)OC1CC</smiles>

Figure 7. a) Photocaged DNA-metalating agents, with the photolabile ligand in blue. b) Schematic representation of a metalated guanine.

\section{Photoisomerizable groups}

The use of photolabile protecting groups can be appropriate for the activation or deactivation of DNA recognition events, but the uncaging process is irreversible. Reversibility can be achieved by using photoisomerizable groups, i.e., molecules with two kinetically stable conformations that can be interconverted by irradiation with light. Our group published in 2000 the first example of a peptide whose interaction with the DNA could be modulated with light, using an azobenzene unit to link two GCN4 basic regions (Figure 8). ${ }^{32}$ Azobenzenes present the peculiarity of being isomerizable among the cis and trans forms. This produces large conformational changes in their geometry, which can be exploited for controlling the interaction of designed peptides with the DNA, so that in our case the cis isomer interacts about 60 -fold better with the consensus DNA sequence than the trans isomer. The cis conformation favours DNA binding by positioning both basic regions in the correct orientation to simultaneously interact with their respective half-sites, while the trans conformation forces a divergent geometry in the basic regions that does not favour DNA binding. Whereas trans to cis isomerization could be carried out in the presence of DNA, the cis to trans reisomerization was not achieved, due to the high affinity of the cis isomer for its consensus DNA.
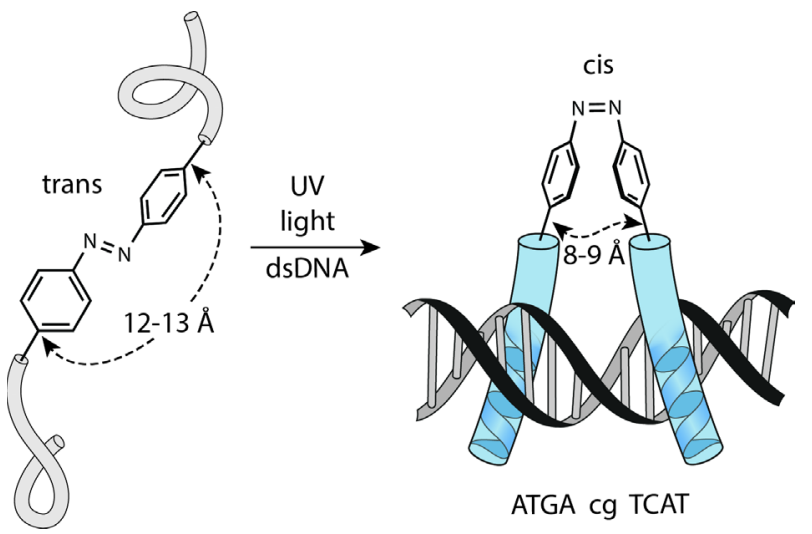

Figure 8. Schematic illustration of the light-promoted azobenzene isomerization and ensuing DNA binding. 
a)
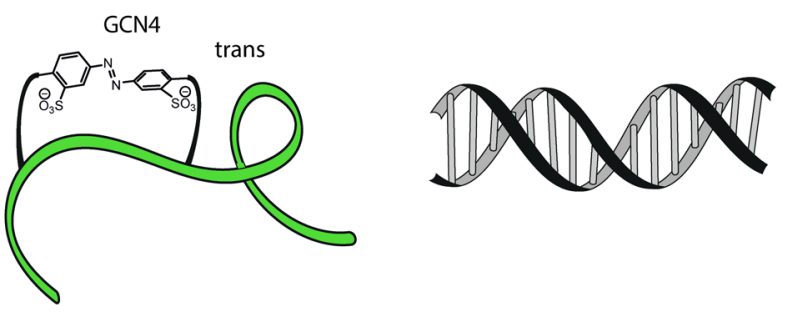

b)

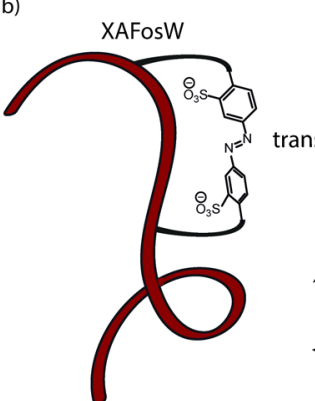

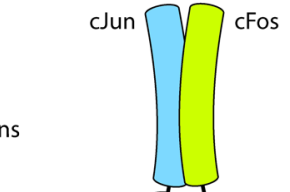

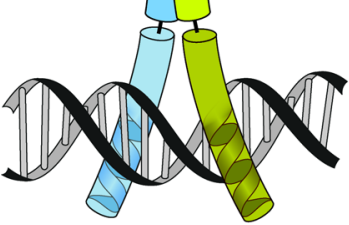

ATGA c TCAT

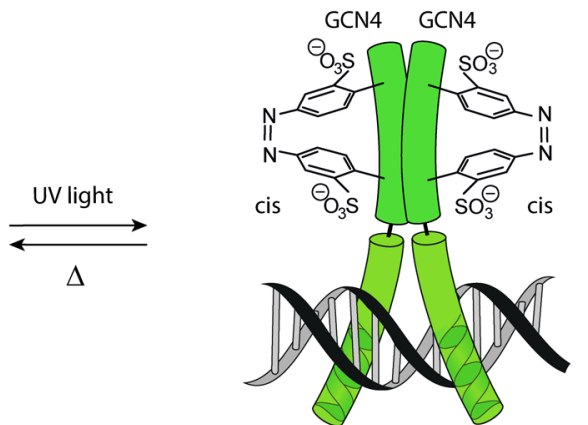

ATGA $\subset$ TCAT

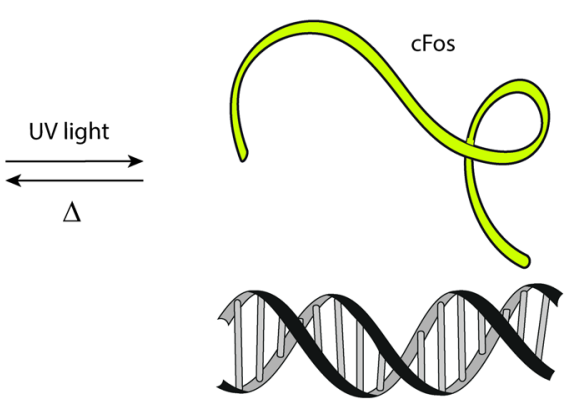

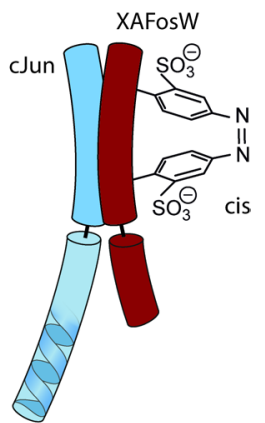

Figure 9. Representation of the light-mediated azobenzene isomerization in a) GCN4 peptide, switching on the DNA binding event; and b) XAFosW peptide, switching off the interaction of cFos/cJun complex with the DNA.

In another version of this strategy, Woolley et al. demonstrated the reversible DNA binding of azobenzene-modified GCN4 peptides. ${ }^{33}$ In this case, an azobenzene moiety, connecting two residues in the leucine zipper at $i$ and $i+7$ positions, was used to control the helicity of an $\alpha$-helical peptide, such that the cis isomer stabilizes the $\alpha$-helix conformation more than the trans isomer. Therefore, the cis isomer interacts 20 times better with the consensus DNA (Figure 9a). The group applied a similar strategy to photocontrol the interaction of the heterodimeric cFos/cJun complex with its target DNA (Figure 9b)..$^{34}$ In this case, the dominant-negative peptide XAFosW was modified with the azobenzene motif; as with GCN4, the cis isomer promotes $\alpha$-helical folding and favors the dimerization with the cJun peptide, thereby displacing cFos and disrupting the interaction of the cJun/cFos heterodimer with the DNA. This process was made fully reversible upon thermal isomerization of the azobenzene unit to the trans state. In their study, Woolley et al. demonstrated for the first time, the successful application of artificial peptides for the photocontrol of transcription in live cells. Finally, it is worth mentioning that azobenzenes have also been recently used for controlling the DNA binding of zinc fingers (ZFs) ${ }^{35}$ and small molecules. ${ }^{36}$

The group of Peacock reported that the DNA binding of GCN4 basic regions could be promoted by light-induced intermolecular dimerization of two anthracene-tagged basic regions. ${ }^{17}$ Thus, monomeric GCN4 peptides modified with anthracene units at the C-terminus were efficiently dimerized upon irradiation in the presence of the target ATF/CREB site, resulting in stronger DNA binders after the photocrosslinking (Figure $3 b)$. However, the reversibility of this process was not reported, probably due to the need of high energy light or high temperature to induce the reverse reaction.

\subsection{METAL-MEDIATED dsDNA BINDING}

Metals play essential roles in Biology, in most of the cases through their selective coordination to biomolecules and biopolymers. This is, for instance, the case of zinc finger TFs, which require the coordination of $\mathrm{Zn}^{2+}$ to two Cys and two His residues to fold into the functional $\beta \beta \alpha$ domains that selectively recognize the DNA. ${ }^{37}$ The ZF motif has inspired a number of artificial constructs whose DNA interaction can be controlled by metal ions. These DNA binders can be grouped into three classes based on the role of the metal center: activating agent, deactivating agent, or supramolecular connector.

\section{Activation of the interaction}

In 1993, the group of Schepartz reported the first example of a synthetic peptide whose DNA interaction relies on the formation of a terpyridine (tPy) $-\mathrm{Fe}^{2+}$ coordination complex acting as a linker between two basic region peptides derived from the GCN4 TF (Figure 3c). ${ }^{18}$

Inspired by Schepartz's design, in 2013 our group reported a GCN4-based peptide that can be driven towards two different DNA sequences depending on its dimerization mode (Figure 10). ${ }^{38}$ This switchable peptide consisted on a GCN4 basic region sequence modified with a redox-sensitive Cys residue at its $\mathrm{N}$-terminus, and a metal-chelating tPy ligand at its $\mathrm{C}$ terminus. It was shown that incubation of the monomeric basic region peptide with $\mathrm{Ni}^{2+}$ promoted the selective binding to the natural ATF/CREB site (5'-ATGAcgTCAT-3'), while selective oxidation of the cysteine residue to a disulfide with DTNB (5,5'-dithiobis-(2-nitrobenzoic acid)) promoted the specific recognition of an alternative sequence featuring the two half-sites swapped (5'-TCATcgATGA-3'). This switch is made possible by the different arrangement of the basic regions in each case. Importantly, reduction or oxidation of the disulfide bond by treatment with TCEP (tris(2carboxyethyl)phosphine) or DTNB, in presence of the nickel 
salts, reversibly drives the peptide to either DNA site. This system represents the first example of a synthetic peptide that can bind to more than one specific DNA sequence in response to external stimuli.

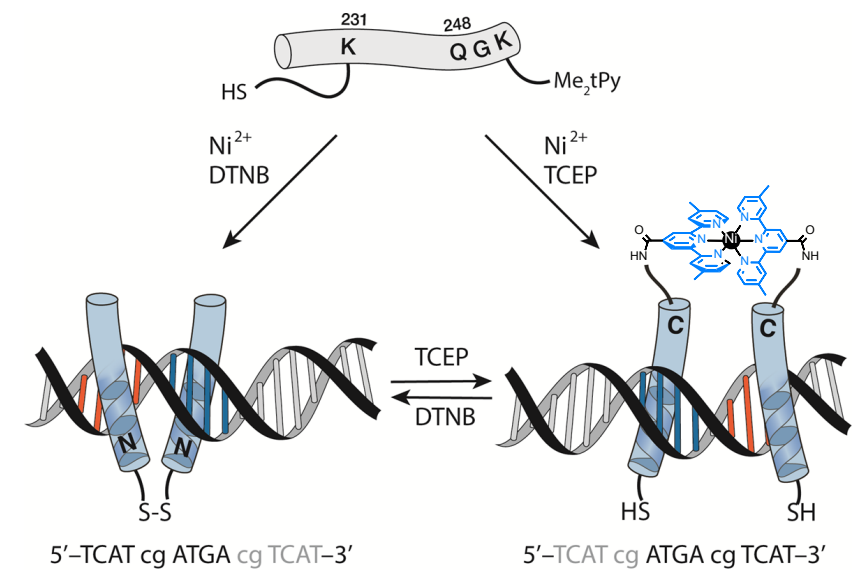

Figure 10. Representation of the dynamic selection of two different consensus DNA sites. The C-terminal metallo-dimer recognizes the direct site, while the $\mathrm{N}$-terminal disulfide dimer binds the inverted sequence.

In 2014, the group of Peacock reported a complementary strategy to achieve metal-regulated DNA binding. In this case, short peptides based on the basic region of GCN4 were covalently dimerized with either bipyridine or terpyridine units. This metal-chelating linker undergoes a conformational rearrangement upon $\mathrm{Cu}^{2+}$ or $\mathrm{Zn}^{2+}$ coordination, which in turn promotes sequence-selective DNA binding (Figure 3d). ${ }^{19}$

Inspired in the $\mathrm{Fe}^{2+} \mathrm{GCN} 4$ peptide dimers described by Schepartz, the group of Tezcan described in 2016 a modified bZIP basic region in which the metallic centers acted both as linkers as well as $\alpha$-helix inducers. This was possible thanks to the introduction of His and phenanthroline (Phen) ligands at $i$ and $i+7$ positions of $C$-terminal basic region of a bZIP protein. They showed that incubation of the peptide with $\mathrm{Ni}^{2+}$ promoted a high affinity and selective binding to the target ATF/CREB site (Figure 11). ${ }^{39}$

a)
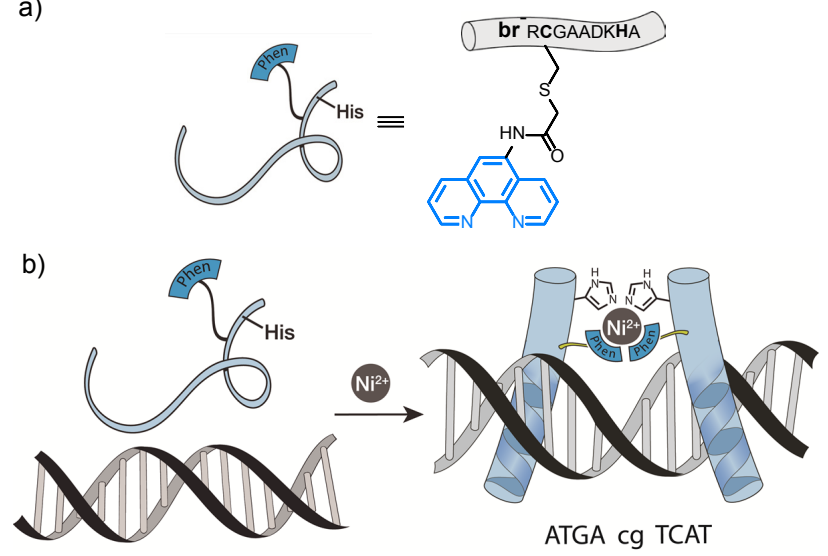

Figure 11. Schematic representation of the $\mathrm{Ni}^{2+}$-mediated dimerization strategy used by Tezcan and coworkers.

As outlined in the introduction, monomeric GCN4 basic regions do not interact with their target DNA sequence with significant affinity, in part because of the entropic cost associated with the folding of the peptide chain into an $\alpha$-helix.
Peptide stapling has emerged as a powerful strategy for stabilizing the $\alpha$-helical conformation, and thus it can be used for promoting DNA-binding of monomeric basic regions. ${ }^{40}$ In 2017, we described a metal-mediated stapling strategy that allows a high affinity and selective DNA binding of the basic region of GCN4 (Figure 12). ${ }^{4}$ The peptide fragment consisted of the basic region of GCN4 in which residues Leu230 and Arg234 were replaced by histidines (brHis 2 ). The resulting peptide, brHis2, displayed high affinity and sequence-specific DNA binding after addition of $\mathrm{PdCl}_{2}$ (en) (en, ethylenediamine). Circular dichroism (CD) spectroscopy showed that brHis2 is largely unstructured in solution, but folds into an $\alpha$ helix only upon binding to its consensus DNA sequence in the presence of $\mathrm{PdCl}_{2}(\mathrm{en})$. The interaction with the DNA could be inhibited by adding a $\mathrm{Pd}^{2+}$ chelator (DEDTC, sodium diethyldithiocarbamate), which removes the palladium and therefore triggers the disassembly of the peptide-DNA complex. Interestingly, we also found that the peptide brHis2 is effectively internalized only in the presence of the palladium reagent, after formation of the metal-clipped peptide, becoming the first example of metal-promoted cellular internalization. Very recently we reported that this type of metallopeptide can be catalytically active and promote palladium-mediated depropargylation reactions inside live cells. ${ }^{41}$

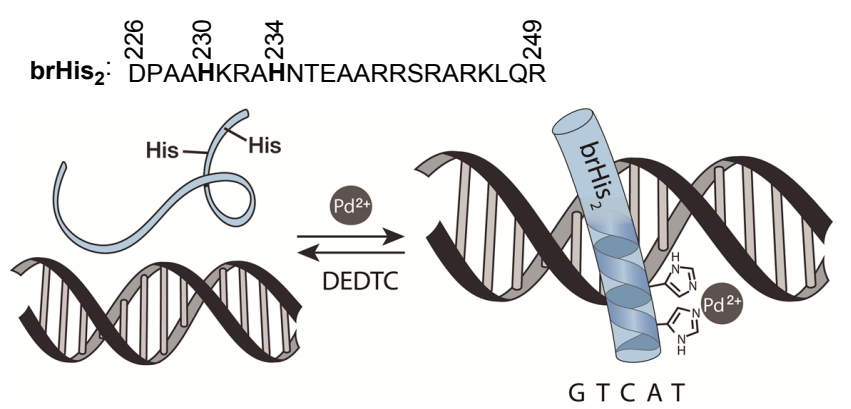

Figure 12. Top: Sequence of the brHis 2 peptide with mutated residues respect to the natural sequence in bold. Bottom: Schematic illustration of the $\mathrm{Pd}^{2+}$-mediated assembly.

\section{Deactivation of the interaction}

In contrast with these results, in which metals trigger the DNA binding event, in 2005 Yamamura's group showed that metals could also be applied as a chemical stimulus to inhibit the DNA binding affinity of designed peptides. This was demonstrated with a conjugate between a ZF TF (zif268) and the calcium binding region of troponin C. 42 The calcium binding motif has a flexible structure in the absence of the metal, allowing the interaction of the ZF peptide with its consensus DNA; addition of $\mathrm{Ca}^{2+}$ ions induces the folding of the troponin $\mathrm{C}$ region, making the peptide to adopt a rigid structure, and thereby reducing the affinity of the ZF motif for its target DNA. Similarly, Futaki's group described a metal-responsive DNA binding switch in which the leucine zipper of a GCN4 peptide was derivatized with cysteine residues functionalized with iminodiacetic acid (Ida). While the Ida-modified GCN4 peptide retained the natural DNA binding properties of the GCN4 dimer, when such chains coordinate $\mathrm{Co}^{2+}$ ions, the helical content of the peptide decreases and consequently its affinity with DNA is drastically reduced (Figure 13).43 Importantly, addition of a $\mathrm{Co}^{2+}$ chelator (EDTA, ethylenediaminetetraacetic acid) recovered the DNA binding. 


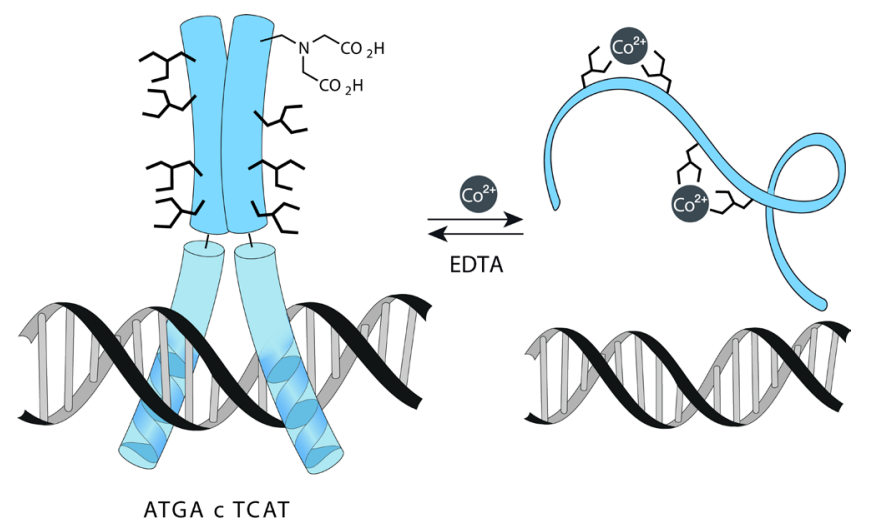

Figure 13. Representation of the $\mathrm{Co}^{2+}$-mediated DNA unbinding event. Iminodiacetic acid (Ida) residues are shaded in grey.

Strategies based on metal coordination have also been applied for modulating the DNA intercalation of small molecules such as scorpiand-like ligands equipped with a macrocyclic ring linked to a pyrene unit through a desined connector (Figure 14). The planar pyrene intercalates into the DNA when the ligand is in the open conformation, but addition of $\mathrm{Cu}^{2+}$ ions induces a conformational change in the linker, which participates in the formation of the coordination complex, forcing the ligand to acquire a closed conformation and blocking the intercalation of the pyrene unit into the DNA.44

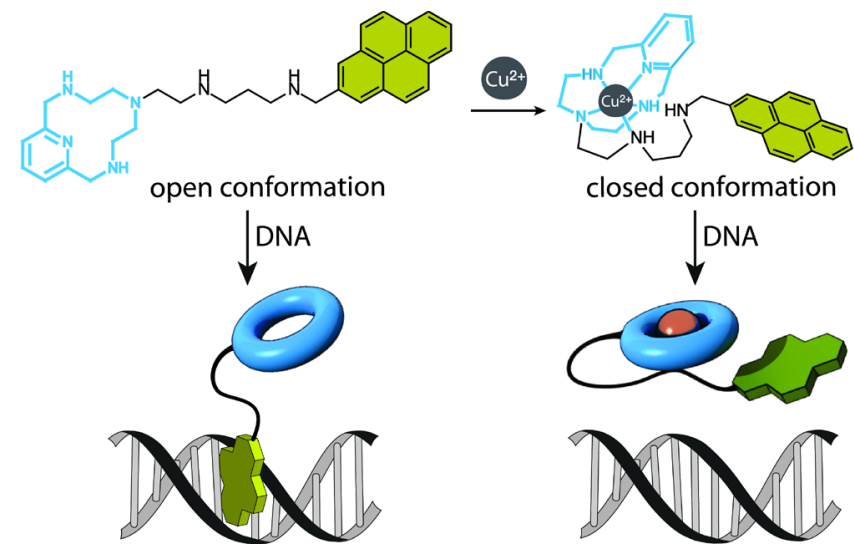

Figure 14. Schematic representation of the $\mathrm{Cu}^{2+}$-promoted inhibition of the DNA binding.

\section{Metals as connectors in multicomponent dsDNA binders}

In 2014, we reported the application of metal-promoted selfassembly for the specific bivalent recognition of DNA. We showed that $\mathrm{Ni}^{2+}$ ions mediate the assembly and simultaneous bivalent DNA interaction of a brHis 2 peptide and a bisbenzamidine equipped with a bipyridine (bpy) unit (Figure 15). ${ }^{2}$ The addition of $\mathrm{Ni}^{2+}$ induces the folding of the peptide into an $\alpha$-helical conformation by stapling the $\mathrm{N}$-terminal turn, and at the same time mediates the interaction with the bisbenzamidine containing a bipyridine ligand. This system efficiently assembles only in the presence of the target DNA. Importantly, in contrast to previously reported covalent conjugates that do bind to mutated DNA sequences with substantial affinity, no interaction was observed with DNA sequences with a single mutation on the recognition site, highlighting the higher selectivity obtained with non-covalent systems. Remarkably, the addition of an external $\mathrm{Ni}^{2+}$ chelator (EDTA) promoted the disassembly of the DNA complex, demonstrating that the process is reversible.<smiles>C#CCOc1ccc(-c2ccc(C(=O)NNCCNCCNc3ccc(C(N)=[NH2+])cc3)nc2)nc1</smiles>

b)

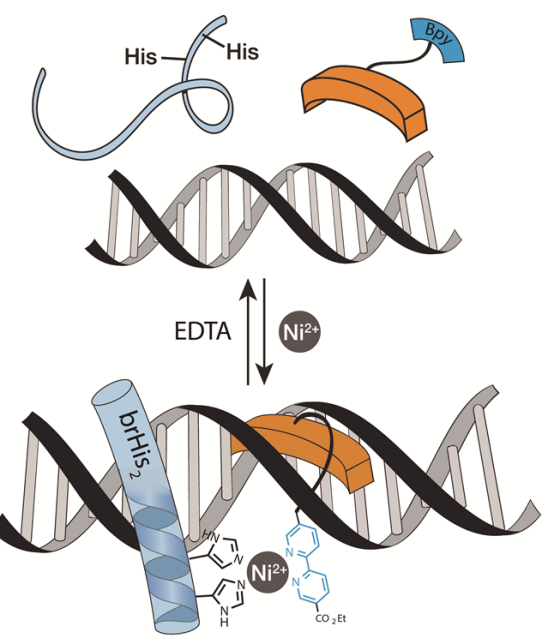

TCAT A ATT T

Figure 15. a) Structure of the bipyridine-bisbenzamidine motif. b) Illustration of the $\mathrm{Ni}^{2+}$-mediated binary DNA binding.

This $\mathrm{Ni}^{2+}$-mediated binary assembly allows the specific recognition of relatively short DNA tracts of 9 base pairs, still far from the typical extended sequences recognized by natural DNA binding proteins. However, by merging the $\mathrm{Ni}^{2+}$ mediated strategy with our work with AT-hook bivalent conjugates (Figure 4b), we demonstrated the $\mathrm{Ni}^{2+}$-promoted specific recognition of long DNA sites of 12 base pairs. This was possible by the addition of a metal-chelating bpy at the $\mathrm{N}$ terminus of a binary GCN4/AT-hook conjugate (bpy-brHk, Figure 16). ${ }^{45}$ The peptide bpy-brHk binds DNA in a bivalent manner and in the presence of $\mathrm{Ni}^{2+}$ traps the basic region derivative brHis 2 , driving the interaction with the extended target DNA sequence. Importantly, the interaction can be also reversed by addition of EDTA to the preformed complex.

Following these efforts to recognize extended DNA sequences, we recently found that adding one metal-chelating bpy unit at each end of the AT-hook minor groove binder (Hk-bpy2), it is possible to achieve a completely metallosupramolecular recognition of composite target sites featuring the binding sequences of the AT-hook minor groove binder flanked by two AP1 half sites (Figure 17).46 Thus, the AT-hook derivative Hk-bpy2 does not bind DNA by itself with enough affinity, but in presence of $\mathrm{Ni}^{2+}$ salts and the consensus DNA sequence, it recruits two brHis 2 units to the adjacent major grooves, driving the binding to an extended target DNA sequence of 12 base pairs with good sequence selectivity. We did not observe interaction with a DNA lacking the AT-hook binding site, which contrasts with the previous ternary covalent conjugates that do bind to this mutated DNA sequence with substantial affinity.47,48 This result further highlights the good performance of non-covalent systems in terms of selectivity. As in the previous cases, addition of nickel chelating EDTA led to the dissociation of the metallosupramolecular-DNA complex. 
a)

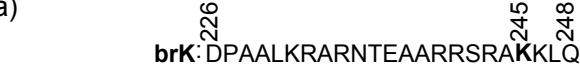

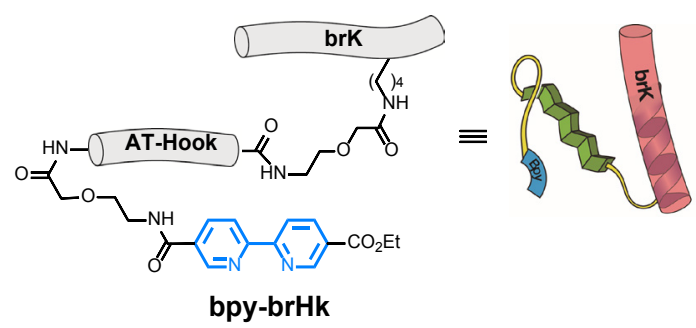

b)

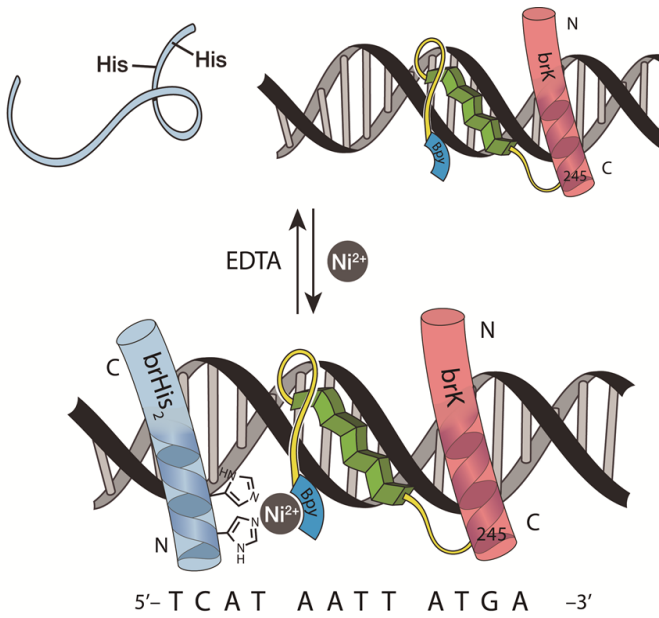

Figure 16. a) Structure of the bpy-brHk conjugate. b) Representation of the $\mathrm{Ni}^{2+}$-mediated ternary DNA binding.

a) Hk:KPRGRPKK<smiles>CCOC(=O)c1ccc(-c2ccc(C(=O)O[PH3+])cc2)nc1</smiles>

b)

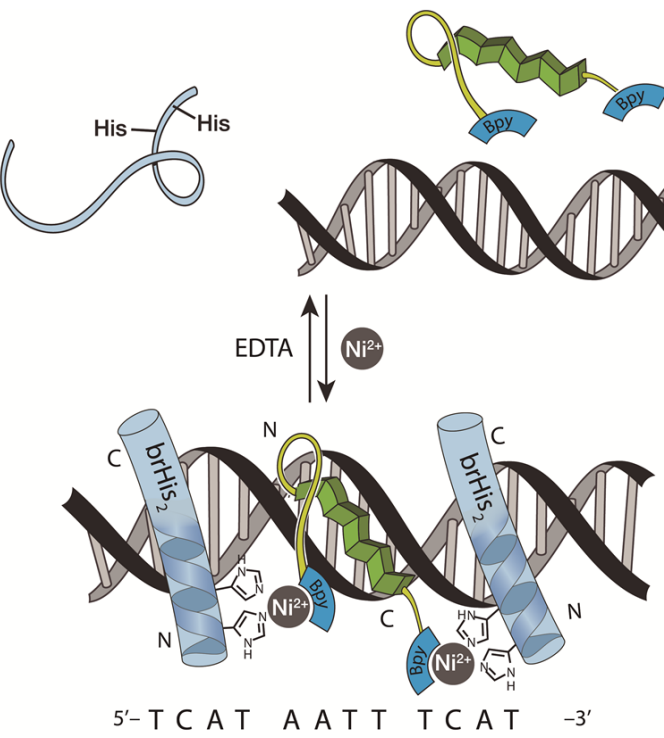

Figure 17. a) Structure of Hk-bpy2. b) Representation of the $\mathrm{Ni}^{2+}$-mediated ternary DNA binding.

\section{STIMULI-RESPONSIVE BINDING TO GQ DNA}

\subsection{RECOGNITION OF GQs}

As indicated in the introduction, DNA GQs play relevant biological roles, e.g., in the maintenance of telomeres or in the regulation of gene transcription. ${ }^{7}$ Therefore, there have been many efforts to develop synthetic systems that can specifically recognize GQs, and thereby control their formation and modulate their biological function. $49,50,51$ In general, molecules that stabilize GQs have been shown to inhibit telomerase activity or gene expression, while molecules that disrupt the quadruplex structure lead to an enhancement in the activity. ${ }^{52}$

The two most commonly used GQs targets are h-telo (based on TTAGGG repeats), that is present in telomeres and forms antiparallel GQs in sodium buffers (Figure 2a),53 and the DNA sequence present in the promoter of the c-myc oncogene (5'-TTGA-GGG-TGGG-TA-GGG-TGG-GTAA-3'), which forms a parallel GQ structure (Figure $2 \mathrm{~b}$ ). ${ }^{49}$

\subsection{LIGHT-MEDIATED GQ BINDING}

\section{Photolabile caging groups}

Common photouncaging processes involve the masking of a GQ ligand with a photolabile group to hamper the binding, so that the DNA interaction is restored after irradiation and removal of the protecting group. ${ }^{54,55}$ Generally, the interaction of the uncaged ligand stabilizes the GQ structure, but does not promote a change on its folding. This uncaging strategy has been used for inhibiting the activity of telomerase, ${ }^{54}$ and the expression of different GQ containing genes (including c-myc) in live cells. 55

Metal complexes capable of coordinating to GQs can also be engineered to show stimuli-responsive properties. ${ }^{56,57}$ In 2016, our group reported the light-promoted selective modification of unpaired guanines flanking the GQ of the c-myc promoter, using caged ruthenium complexes (Figure 18). ${ }^{3,58}$ Our design was based on the use of bulky ruthenium complexes, $[\mathrm{Ru}(\mathrm{tpy})(\mathrm{bpy}) \mathrm{X}]^{2+}$, in which $\mathrm{X}$ is a photolabile thioether ligand. These complexes exchange the thioether ligand with water after irradiation, generating a reactive aquo complex that binds the more accessible guanines. In vitro experiments demonstrated that these ruthenium complexes metallated the c-myc GQ, as we observed a clean formation of a monoruthenated adduct only in the presence of light. The modification was found to occur at G3, which is not involved in the formation of the G-tetrads, but adjacent to them (Figure 18, left). Curiously, CD spectroscopy revealed that this metalation disrupts the GQ folding. We also found that this reaction has biological consequences, and that cells treated with this complex showed an enhancement in the transcription of the cmyc gene after irradiation.

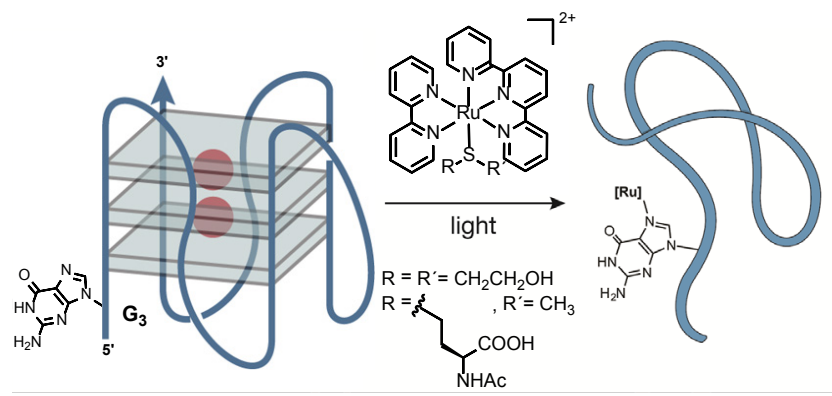

Figure 18. Representation of the light-promoted ruthenation and subsequent unfolding of the GQ. 
Recently, Galan and coworkers reported a photoresponsive stilbene derivative that induces the reversible unfolding of h-telo GQ. This ligand was found to intercalate between the Gtetrads and thereby disrupt the quadruplex structure; photooxidation of the stilbene restored the original GQ folding (Figure 19). ${ }^{59}$

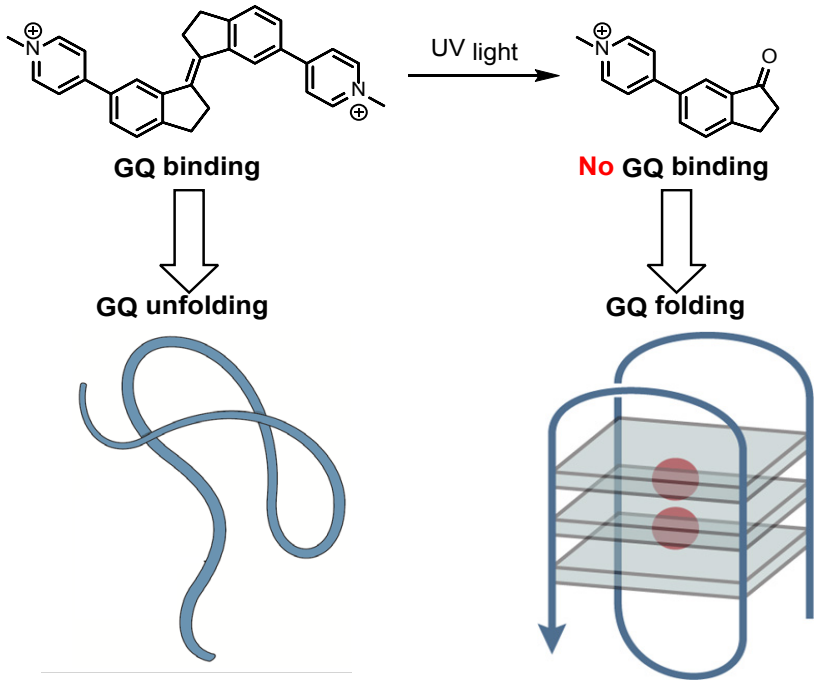

Figure 19. Representation of the light-promoted folding of GQ after photo-oxidation of stilbene.

\section{Photoisomerizable groups}

Zhou and colleagues described in 2010 a light-responsive azobenzene derivative that was capable of promoting the $h$ telo GQ-folding when used in the trans form (Figure 20). This trans isomer presents a planar azobenzene core that can endstack on top of the GQ structure. Remarkably, irradiation with UV light produces the cis isomer, which compromises the $\pi$ stacking and drives the unfolding process. ${ }^{60}$ The switching was shown to be completely reversible and was exploited to regulate the function of exonuclease I, which catalyzes DNA hydrolysis reactions only after disruption of the GQ structure.

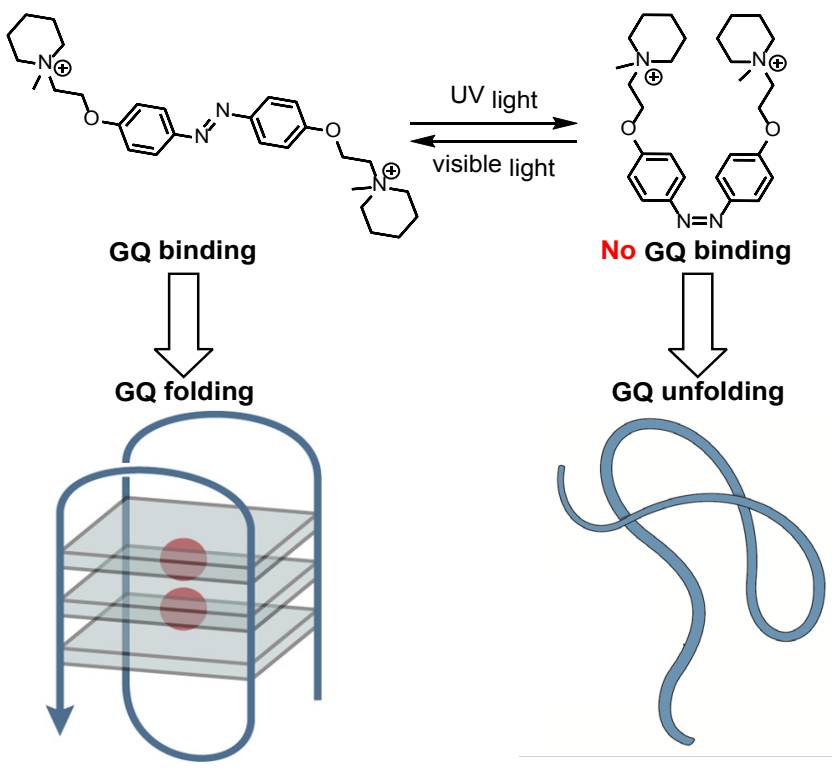

Figure 20. Illustration of the light-promoted azobenzene isomerization and consequent GQ binding/unbinding.

\subsection{REDOX CONTROLLED GQ BINDING}

Compounds that can be activated under reducing conditions are of high interest because tumoral cells are known to be in a hypoxic environment. In 2018, Vilar and coworkers described the first example of redox-promoted GQ binder (Figure 21) based on the reduction of an octahedral Pt(IV) complex (unable to interact with the quadruplex due to the presence of axial ligands) to an square-planar Pt(II) derivative (with the appropriate geometry for stacking with the GQ). ${ }^{61}$ Spectroscopic studies showed that, while the Pt(IV) complex is not able to bind the quadruplexes of h-telo or c-myc, upon addition of the reducing agent glutathione, the resulting $\mathrm{Pt}(\mathrm{II})$ species produced in situ binds the GQ with high affinity.

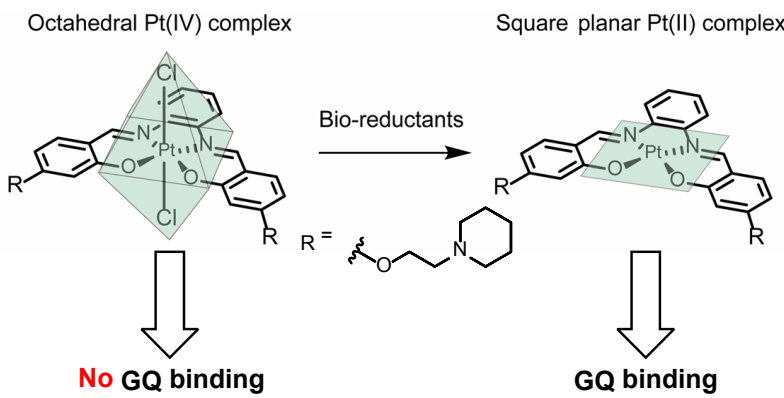

Figure 21. Schematic illustration of the redox-promoted GQ binding.

\subsection{METAL REGULATED GQ BINDING}

Metals have also been used to switch the folding of GQs. Mergny and coworkers described in 2008 the use of $\mathrm{Cu}^{2+}$ ions to promote the reversible unfolding of the GQ of h-telo (Figure 22). ${ }^{62}$ In this work, a bisquinolinium ligand, which was able to selectively bind and stabilize the GQ, changes its geometry upon coordinating $\mathrm{Cu}^{2+}$ ions. This triggers its DNA dissociation and the unfolding of the quadruplex structure. Importantly, addition of a copper chelator (EDTA) regenerates the free ligand and restores the binding and folding ability of the ligand.

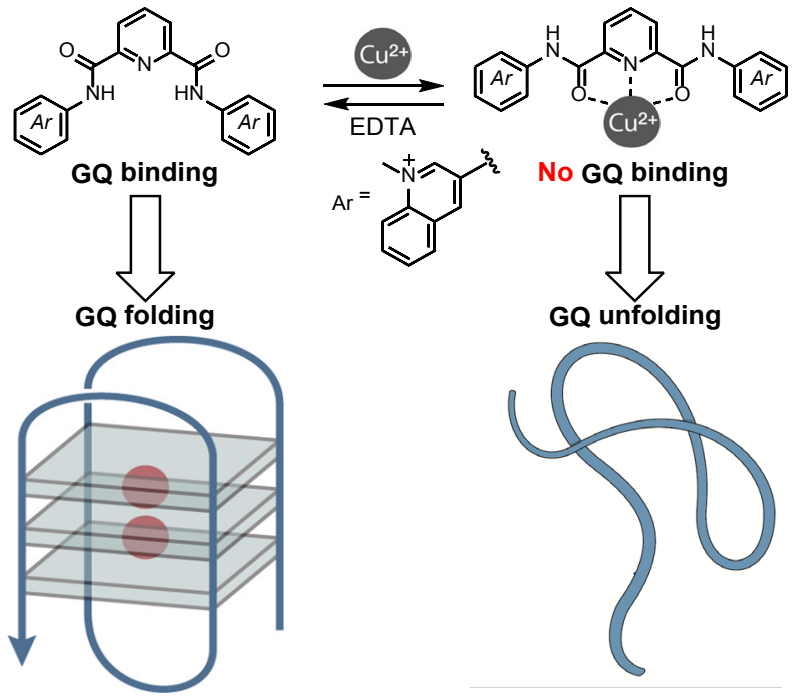

Figure 22. Representation of the $\mathrm{Cu}^{2+}$-mediated GQ folding/unfolding. 


\section{CONCLUSIONS AND OUTLOOK}

Synthetic DNA binders that can mimic the recognition properties of natural TFs are of great interest as potential regulators of cellular gene expression. However, obtaining systems capable of binding designed target sequences with high affinity and specificity is certainly challenging. Moreover, it would be highly desirable to implement stimuli-responsible properties in these binders, as this could allow for the spatiotemporal control of their function. In this review we have discussed some of the more relevant strategies used so far, summarized in Table 1.

The most successful synthetic DNA binding peptides are based on miniaturized versions of natural TFs, mainly bZIP proteins like GCN4. The absence of a universal peptide-DNA recognition code makes extremely difficult to extend this type of recognition to other systems than those occurring in Nature. ${ }^{63}$ The development of new computational methods that allow for the efficient prediction of peptide-DNA interactions may lead to improved designs and to expand the sequences that can be recognized. Combining rational design with selection protocols might also prove to be very useful in the near future.

An especially appealing strategy to bind DNA using artificial synthetic units is based on the supramolecular combination of different recognition units. We have demonstrated that such combination can be achieved through metal-coordinating linkers. In this way, it is not only possible to regulate the interaction with the DNA, but also to obtain better selectivity (Table 1). This strategy has the potential additional advantage of enabling the combinatorial interaction with a large number of sites using a relatively small set of monomeric units.

\begin{tabular}{|c|c|c|c|c|c|c|c|c|}
\hline & \multirow{3}{*}{$\begin{array}{ll} & \text { Ref. } \\
1 & \\
\end{array}$} & \multirow{3}{*}{$\begin{array}{c}\begin{array}{c}\mathbf{K}_{\mathrm{D}} \\
(\mathrm{nM})\end{array} \\
38 \\
\end{array}$} & \multirow{3}{*}{$\begin{array}{c}\text { Reversible } \\
x \\
\end{array}$} & \multirow{3}{*}{$\begin{array}{c}\begin{array}{c}\text { DNA } \\
\text { binding }\end{array} \\
\mathrm{ON} \\
\end{array}$} & \multirow{3}{*}{$\begin{array}{c}\begin{array}{c}\text { Regulation of } \\
\text { transcription }\end{array} \\
\text { n.d. } \\
\end{array}$} & \multirow{3}{*}{$\begin{array}{c}\begin{array}{c}\text { Sequence } \\
\text { selectivity }\end{array} \\
\text { moderate } \\
\end{array}$} & \multirow{3}{*}{$\begin{array}{c}\text { GQ } \\
\text { Folding } \\
- \\
\end{array}$} \\
\hline & & & & & & & & \\
\hline \multirow{11}{*}{$\begin{array}{l}\mathbf{L} \\
\mathbf{I} \\
\mathbf{G} \\
\mathbf{H} \\
\mathbf{T}\end{array}$} & \multirow{6}{*}{$\begin{array}{l}\text { Photolabile } \\
\text { protecting groups }\end{array}$} & & & & & & & \\
\hline & & 30 & 390 & $x$ & $\mathrm{ON}$ & n.d. & low & - \\
\hline & & 54,55 & - & $x$ & $\mathrm{ON}$ & $\checkmark$ & - & unchanged \\
\hline & & 3 & - & $x$ & $\mathrm{ON}$ & $\checkmark$ & - & unfolding \\
\hline & & 27 & 12 & $x$ & OFF & n.d. & moderate & - \\
\hline & & 59 & - & $x$ & $\mathrm{OFF}$ & n.d. & - & folding \\
\hline & \multirow{4}{*}{ Photoisomerization } & 32 & n.d. & $x$ & $\mathrm{ON}$ & n.d. & moderate & - \\
\hline & & 33 & n.d. & $\checkmark$ & ON/OFF & n.d. & n.d. & - \\
\hline & & 34 & n.d. & $\checkmark$ & ON/OFF & $\checkmark$ & n.d. & - \\
\hline & & 60 & - & $\checkmark$ & ON/OFF & n.d. & - & reversible \\
\hline & Photodimerization & 17 & 800 & $x$ & $\mathrm{ON}$ & n.d. & low & - \\
\hline \multirow{10}{*}{$\begin{array}{l}\mathbf{M} \\
\mathbf{E} \\
\mathbf{T} \\
\mathbf{A} \\
\mathbf{L}\end{array}$} & $\mathrm{tPy}-\mathrm{Fe}^{2+}$ & 18 & 0.13 & n.d. & $\mathrm{ON}$ & n.d. & high & - \\
\hline & $\mathrm{tPy}-\mathrm{Ni}^{2+}$ & 38 & 300 & $\checkmark$ & ON/OFF & n.d. & moderate & - \\
\hline & bpy/tPy $-\mathrm{Cu}^{2+} / \mathrm{Zn}^{2+}$ & 19 & $200-1440$ & $\checkmark$ & ON/OFF & n.d. & low & - \\
\hline & His/Phen-Ni ${ }^{2+}$ & 39 & 65 & n.d. & $\mathrm{ON}$ & n.d. & moderate & - \\
\hline & His- $\mathrm{Pd}^{2+}$ & 4 & 24 & $\checkmark$ & ON/OFF & n.d. & high & - \\
\hline & $\mathrm{Ca}^{2+}$ & 42 & 5.8 & n.d. & OFF & n.d. & moderate & - \\
\hline & Ida-Co ${ }^{2+}$ & 43 & 22 & $\checkmark$ & $\mathrm{ON} / \mathrm{OFF}$ & n.d. & n.d. & - \\
\hline & $\mathrm{Cu}^{2+}$ & 44 & $>1 \mu \mathrm{M}$ & $x$ & OFF & n.d. & n.d. & - \\
\hline & His-Ni ${ }^{2+}$ & $2,45,46$ & $22-450$ & $\checkmark$ & ON/OFF & n.d. & high & - \\
\hline & $\mathrm{Cu}^{2+}$ & 62 & - & $\checkmark$ & $\mathrm{ON} / \mathrm{OFF}$ & n.d. & - & reversible \\
\hline \multicolumn{2}{|c|}{ REDOX } & 61 & - & $x$ & $\mathrm{ON}$ & n.d. & - & unchanged \\
\hline
\end{tabular}

Table 1. Comparison of the different stimuli-responsive approaches discussed in the review. n.d. = not determined. Sequence selectivity has been assigned as high when a single mutation in the target DNA implies loss of DNA binding, and low when after several mutations in the target DNA sequence, some DNA binding is still retained.
Metals have also been used as external triggers to activate and deactivate the DNA binding of different type of systems. This trolled using light, provided suitable synthetic units containing photolabile caging groups or azobenzene units are built (Table 1). In this context, an interesting issue that deserves to be explored is the application of light-driven rotary molecular motors to control the DNA-binding. Their $360^{\circ}$ unidirectional rotation in several steps, high quantum yields and excellent photostability make them ideal candidates to precisely regulate the conformation and therefore the DNA binding properties. 64

Undoubtedly, a major current challenge consists of translating some of these technologies to real, living systems, in order to control gene expression. In this context, the light-based approaches are especially appealing and, to date, the only ones applied for regulation of transcription inside living cells (Table 1). However, further work is still required to implement NIR-sensitive control elements in order to avoid cellular damage and allow deeper in vivo applications. ${ }^{3,34}$ The use of $\mathrm{pH}$ - or redox-based switches can also be very useful, when they are associated to different biological states. ${ }^{61}$ All these concepts apply to both dsDNA or other relevant DNA motifs, such as GQs.

Finally, although it is not usually considered in the design, an essential factor for in vivo applications of these systems has to do with their efficient biological transport and cellular uptake. If cell internalization can be triggered in response to an external stimulus, like with our palladium clip, ${ }^{4}$ we have an additional spatiotemporal control of the activity. An interesting possibility is the design of photolabile caging groups that allow the cellular internalization after the cleavage. ${ }^{29}$ external regulation of the DNA interaction can also be con- 


\section{AUTHOR INFORMATION}

\section{Corresponding Author}

* e-mail: jessica.rodriguez.villar@rai.usc.es

* e-mail: joseluis.mascarenas@usc.es

\section{Biographies}

Jéssica Rodríguez received her Ph.D. from University of Santiago de Compostela in 2016. She is currently a postdoctoral researcher at LHFA in Toulouse, France.

Jesús Mosquera received his Ph.D. from University of Santiago de Compostela in 2014. He is currently a lecturer at University of Strathclyde, Scotland.

Soraya Learte-Aymamí is currently a Ph.D. student at the University of Santiago de Compostela.

M. Eugenio Vázquez received his Ph.D. from University of Santiago de Compostela in 2011, where he is currently full professor.

José Luis Mascareñas completed his Ph.D. in 1988 at the University of Santiago de Compostela, where he is currently full professor.

\section{ACKNOWLEDGMENT}

Financial support from the Spanish grants SAF2016-76689-R, RED2018-102417-T, RTI2018-099877-B-I00 the Xunta de Galicia (2015-CP082, ED431B 2018/04, ED431C-2017/19 and Centro Singular de Investigación de Galicia accreditation 2019-2022, ED431G 2019/03), the European Union (European Regional Development Fund - ERDF), and the European Research Council (Advanced Grant No. 340055) are gratefully acknowledged.

\section{REFERENCES}

1 Jiménez-Balsa, A.; Pazos, E.; Martínez-Albardonedo, B.; Mascareñas, J. L.; Vázquez, M. E. Temporary electrostatic impairment of DNA recognition: light-driven DNA binding of peptide dimers. Angew. Chem. Int. Ed. 2012, 51, 8825-8829.

2 Sánchez, M. I.; Mosquera, J.; Vázquez, M. E.; Mascareñas, J. L. Reversible supramolecular assembly at specific DNA sites: nickel-promoted bivalent DNA binding with designed peptide and bipyridyl-bis(benzamidine) components. Angew. Chem. Int. Ed. 2014, 53, 9917-9921.

3 Rodriguez, J.; Mosquera, J.; Couceiro, J. R.; Vazquez, M. E.; Mascareñas, J. L. Ruthenation of non-stacked guanines in DNA G-quadruplex structures. Enhancement of the c-MYC gene expression. Angew. Chem. Int. Ed., 2016, 55, 15615-15618.

4 Learte-Aymamí, S.; Curado, N.; Rodríguez, J.; Vázquez, M. E.; Mascareñas, J. L. Metal-dependent DNA recognition and cell internalization of designed, basic peptides. J. Am. Chem. Soc. 2017, 139, 16188-16193.

5 Blackburn, G. M.; Gait, M. J.; Loakes, D.; Williams, D. M. Nucleic Acids in Chemistry and Biology, ISBN-10: 0-85404-654-2, RSCPublishing, Cambridge, 2006; chapter 2.

6 Berman, H. M.; Westbrook, J.; Feng, Z.; Gilliland, G., Bhat, T. N.; Weissig, H.; Shindyalov, I. N.; Bourne, P. E. The Protein Data Bank. Nucleic Acids Res., 2000, 28, 235-242.

7 Varshney, D.; Spiegel, J.; Zyner, K.; Tannahill, D.; Balasubramanian, S. The regulation and functions of DNA and RNA Gquadruplexes. Nat. Rev. Mol. Cell Biol. 2020, 21, 459-474.
8 Burge, S.; Parkinson, G. N.; Hazel, P.; Todd, A. K.; Neidle, S. Quadruplex DNA: sequence, topology and structure. Nucleic Acids Res., 2006, 34, 5402-5415.

9 Yan, Y.; Tan, J.; Ou, T.; Huang, Z.; Gu, L. DNA G-Quadruplex binders: a patent review. Expert Opin. Ther. Pat. 2013, 23, 1495-1509.

10 Garvie, C. W.; Wolberger, C. Recognition of specific DNA sequences. Mol. Cell 2001, 8, 937-946.

11 Vinson, C.; Acharya, A.; Taparowsky, E. J. Deciphering B-ZIP transcription factor interactions in vitro and in vivo. Biochim. Biophys. Acta 2006, 1759, 4-12.

12 Weiss, M. A.; Ellenberger, T.; Wobbe, C. R.; Lee, J. P.; Harrison, S. C.; Struhl, K. Folding transition in the DNA-binding domain of GCN4 on specific binding to DNA. Nature 1990, 347, 575-578.

13 Keller, W.; König, P.; Richmond, T. J. Crystal structure of a bZIP/DNA complex at $2.2 \AA$ Å: determinants of DNA specific recognition. J. Mol. Biol. 1995, 254, 657-667.

14 Boga, S.; Bouzada, D.; García Peña, D.; Vázquez López, M.; Vázquez, M. E. Sequence-specific DNA recognition with designed peptides. Eur. J. Org. Chem. 2018, 2018 (3), 249-261.

15 Pazos, E.; Mosquera, J.; Vázquez, M. E.; Mascareñas, J. L. DNA Recognition by Synthetic Constructs. ChemBioChem 2011, 12 (13), 1958-1973.

16 Talanian, R. V.; McKnight, C. J.; Kim, P. S. Sequence-specific DNA binding by a short peptide dimer. Science 1990, 249, 769-771.

17 Bullen, G. A.; Tucker, J. H.; Peacock, A. F. Exploiting anthracene photodimerization within peptides: light induced sequenceselective DNA binding. Chem. Commun. 2015, 51, 8130-8133.

18 Cuenoud, B.; Schepartz, A. Altered specificity of DNA-binding proteins with transition metal dimerization domains. Science 1993, 259, 510-513.

19 Oheix, E.; Peacock, A. F. A. Metal-ion-regulated miniature DNA-binding proteins based on GCN4 and non-native regulation sites. Chem. Eur. J. 2014, 20, 2829-2839.

20 Sánchez, M. I.; Vázquez, O.; Vázquez, M. E.; Mascareñas, J. L. Sequence-selective DNA recognition with peptidebisbenzamidine conjugates. Chem. Eur. J. 2013, 19, 99239929.

21 Rodriguez, J.; Mosquera, J.; Couceiro, J. R.; Vazquez, M. E.; Mascareñas, J. L. The AT-Hook motif as a versatile minor groove anchor for promoting DNA binding of transcription factor fragments. Chem. Sci., 2015, 6, 4767-4771.

22 Vázquez, M. E.; Caamaño, A. M.; Martínez-Costas, J.; Castedo, L.; Mascareñas, J. L. Design and synthesis of a peptide that binds specific DNA sequences through simultaneous interaction in the major and in the minor groove. Angew. Chem. Int. Ed. 2001, 40, 4723-4725.

23 Vázquez, O.; Vázquez, M. E.; Blanco, J.; Castedo, L; Mascareñas, J. L. Specific DNA recognition by a synthetic, monomeric Cys2His2 zinc-finger peptide conjugated to a minor-groove binder. Angew. Chem. Int. Ed. 2007, 46, 6886-6890.

24 Mosquera, J.; Rodriguez, J.; Vazquez, M. E.; Mascareñas, J. L. Selective DNA-binding by designed bisbenzamidinehomeodomain chimeras. ChemBioChem, 2014, 15, 1092-1095.

25 Rodriguez, J.; Mosquera, J.; Vazquez, O.; Vazquez, M. E.; Mascareñas, J. L. The $\beta \beta \alpha$ fold of zinc finger proteins as a "natural" protecting group. Chemoselective synthesis of a DNA-binding zinc finger derivative. Chem. Commun. 2014, 50, 2258-2260.

26 Young, D. D.; Deiters, A. Photochemical control of biological processes. Org. Biomol. Chem., 2007, 5, 999-1005.

27 Mosquera, J.; Sanchez, M. I.; Vázquez, M. E.; Mascareñas, J. L. Ruthenium bipyridyl complexes as photocleavable dimerizers: deactivation of DNA-binding peptides using visible light. Chem. Commun. 2014, 50, 10975-10978.

28 Mosquera, J.; Sanchez, M. I.; Mascareñas, J. L.; Vázquez, M. E. Synthetic peptides caged on histidine residues with a bisbi- 
pyridyl ruthenium(ii) complex that can be photolyzed by visible light. Chem. Commun. 2015, 51, 5501-5504.

29 Penas, C.; Sánchez, M. I.; Guerra-Varela, J.; Sanchez, L.; Vázquez, M. E.; Mascareñas, J. L. Light-controlled cellular internalization and cytotoxicity of nucleic acid-binding agents: studies in vitro and in zebrafish embryos. ChemBioChem 2016, 17, 37-41.

30 Sanchez, M. I.; Vazquez, O.; Vázquez, M. E.; Mascareñas, J. L. Light-controlled DNA binding of bisbenzamidines. Chem. Commun. 2011, 47, 11107-11109.

31 Imberti, C.; Zhang, P.; Huang, H.; Sadler, P. J. New Designs for Phototherapeutic Transition Metal Complexes. Angew. Chem. Int. Ed. 2020, 59, 61-73.

32 Caamaño, A. M.; Vázquez, M. E.; Martínez-Costas, J.; Castedo, L.; Mascareñas, J. L. A light-modulated sequence-specific DNAbinding peptide. Angew. Chem. Int. Ed. 2000, 39, 3104-3107.

33 Woolley, G. A.; Jaikaran, A. S. I.; Berezovski, M.; Calarco, J. P.; Krylov, S. N.; Smart, O. S.; Kumita, J. R. Reversible photocontrol of DNA binding by a designed GCN4-bZIP protein. Biochemistry, 2006, 45, 6075-6084.

34 Zhang, F.; Timm, K. A.; Arndt, K. M.; Woolley, G. A. Photocontrol of coiled-coil proteins in living cells. Angew. Chem. Int. Ed., 2010, 49, 3943-3946.

35 Murawska, G. M.; Poloni, C.; Simeth, N. A.; Szymanski, W.; Feringa, B. L. Comparative study of photoswitchable zincfinger domain and AT-Hook motif for light-controlled peptide-DNA binding. Chem. Eur. J. 2019, 25, 4965-4973.

36 Heinrich, B.; Bouazoune, K.; Wojcik, M.; Bakowsky, U.; Vázquez, O. ortho-Fluoroazobenzene derivatives as DNA intercalators for photocontrol of DNA and nucleosome binding by visible light. Org. Biomol. Chem., 2019, 17, 1827-1833.

37 Pabo, C. O.; Peisach, E.; Grant, R. A. Design and selection of novel Cys 2 Hisz zinc finger proteins. Annu. Rev. Biochem., 2001, $70,313-340$.

38 Mosquera, J.; Jiménez-Balsa, A.; Dodero, V. I.; Vázquez, M. E.; Mascareñas, J. L. Stimuli-responsive selection of target DNA sequences by synthetic bZIP peptides. Nat. Commun., 2013, 4, 1874.

39 Smith, S. J.; Radford, R. J.; Subramanian, R. H.; Barnett, B. R.; Figueroa, J. S.; Tezcan, F. A. Tunable helicity, stability and DNA-binding properties of short peptides with hybrid metal coordination motifs. Chem. Sci. 2016, 7, 5453-5461.

40 Lyer, A.; Van Lysebetten, D.; Ruiz García, Y.; Louage, B.; De Geest, B. G.; Madder, A. Stapling monomeric GCN4 peptides allows for DNA binding and enhanced cellular uptake. Org. Biomol. Chem. 2015, 13, 3856-3862.

41 Learte-Aymamí, S.; Vidal, C.; Gutiérrez-González, A.; Mascareñas, J. L. Intracellular reactions promoted by bis(histidine) miniproteins stapled using palladium(II) complexes. Angew. Chem. Int. Ed. 2020, 9149-9154.

42 Onoda, A.; Arai, N.; Shimazu, N.; Yamamoto, H.; Yamamura, T. Calcium ion responsive DNA binding in a zinc finger fusion protein. J. Am. Chem. Soc. 2005, 127, 16535-16540.

43 Azuma, Y.; Imanishi, M.; Yoshimura, T.; Kawabata, T.; Futaki, S. Cobalt(II)-responsive DNA binding of a GCN4-bZIP protein containing cysteine residues functionalized with iminodiacetic acid. Angew. Chem. Int. Ed. 2009, 48, 6853-6856.

44 Inclán, M.; Albelda, M. T.; Frías, J. C.; Blasco, S.; Verdejo, B.; Serena, C.; Salat-Canela, C.; Díaz, M. L.; García-España, A.; García-España, E. Modulation of DNA binding by reversible metal-controlled molecular reorganizations of scorpiand-like ligands. J. Am. Chem. Soc. 2012, 134, 9644-9656.

45 Rodriguez, J.; Mosquera, J.; Vazquez, M. E.; Mascareñas, J. L. Nickel-promoted recognition of long DNA sites by designed peptide derivatives. Chem. Eur. J., 2016, 22, 13474-13477.

46 Learte-Aymamí, S.; Rodríguez, J.; Vázquez, M. E.; Mascareñas, J. L. Assembly of a ternary metallopeptide complex at specific DNA sites mediated by an AT-Hook adaptor. Chem. Eur. J., 2020, 26, 8875-8878.

47 Rodríguez, J.; Mosquera, J.; García-Fandiño, R.; Vazquez, M. E.; Mascareñas, J. L. A designed DNA binding motif that recogniz- es extended sites and spans two adjacent major grooves. Chem. Sci. 2016, 7, 3298-3308.

48 Rodríguez, J.; Learte-Aymami, S.; Mosquera, J.; Celaya, G.; Rodríguez-Larrea, D.; Vazquez, M. E.; Mascareñas, J. L. DNAbinding miniproteins based on zinc fingers. Assessment of the interaction using nanopores. Chem. Sci. 2018, 9, 4118-4123.

49 Balasubramanian, S.; Hurley, L. H.; Neidle, S. Targeting Gquadruplexes in gene promoters: a novel anticancer strategy? Nat. Rev. DrugDiscov. 2011, 10, 261-275.

50 Georgiades S. N.; Abd-Karim N. H.; Suntharalingam K.; Vilar, R. Interaction of metal complexes with G-quadruplex DNA. Angew. Chem. Int. Ed. 2010, 49, 4020-4034.

51 Kench, T.; Vilar, R. Metal complexes as G-quadruplex binders. Ann. Rep. Med. Chem. 2020, DOI: 485-515.

52 For a more comprehensive review on GQ DNA binders that induce switching of GQ conformation or respond to external stimulus, see: O'Hagan, M. P; Morales, J. C.; Galan, M. C. Binding and Beyond: What Else Can G-Quadruplex Ligands Do? Eur. J. Org. Chem. 2019, 4995-5017.

53 NMR structure for the $h T E L O$ GQ, PDB: 6IMS.

54 Nakamura, T.; Iida, K.; Tera, M.; Shin-ya, K.; Seimiya, H.; Nagasawa, K: A caged ligand for a telomeric G-quadruplex. ChemBioChem, 2012, 13, 774-777.

55 Murat, P.; Gormally, M. V.; Sanders, D.; Di Antonio, M:; Balasubramanian, S. Light-mediated in cell downregulation of Gquadruplex-containing genes using a photo-caged ligand. Chem. Commun. 2013, 49, 8453-8455.

56 Bertrand, H.; Bombard, S.; Monchaud, D.; Teulade-Fichou, M.P. A platinum-quinacridine hybrid as a G-quadruplex ligand. $J$. Biol. Inorg. Chem. 2007, 12, 1003-1014.

57 Wu, K.; Liu, S.; Luo, Q.; Hu, W.; Li, X.; Wang, F.; Zheng, R.; Cui, J.; Sadler, P. J.; Xiang, J.; Shi, Q.; Xiong, S. Thymines in singlestranded oligonucleotides and G-Quadruplex DNA are competitive with guanines for binding to an organoruthenium anticancer complex. Inorg. Chem. 2013, 52, 11332-11342.

58 Martínez-Calvo, M.; Guerrini, L.; Rodríguez, J.; Álvarez-Puebla, R. A.; Mascareñas, J. L. Surface-Enhanced Raman Scattering detection of nucleic acids exhibiting sterically accessible guanines using ruthenium-polypyridyl reagents. J. Phys. Chem. Lett. 2020, 11, 7218-7223.

59 O'Hagan, M. P.; Haldar, S.; Duchi, M.; Oliver, T. A. A.; Mulholland, A. J.; Morales, J. C.; Galan, M. C. A photoresponsive stiffstilbene ligand fuels the reversible unfolding of G-quadruplex DNA. Angew. Chem. Int. Ed. 2019, 58, 4334-4338.

60 Wang, X.; Huang, J.; Zhou, Y.; Yan, S.; Weng, X.; Wu, X.; Deng, M.; Zhou, X. Conformational switching of G-quadruplex DNA by photoregulation. Angew. Chem. Int. Ed. 2010, 49, 53055309.

61 Bandeira, S.; Gonzalez-Garcia, J.; Pensa, E.; Albrecht, T.; Vilar, R. A redox-activated G-quadruplex DNA binder based on a platinum(IV)-salphen complex. Angew. Chem. Int. Ed. 2018, 57, 310-313.

62 Monchaud, D.; Yang, P.; Lacroix, L.; Teulade-Fichou, M.-P.; Mergny, J.-L. A metal-mediated conformational switch controls G-quadruplex binding affinity. Angew. Chem., Int. Ed. 2008, 47, 4858-4861.

63 Ansari, A. Z.; Mapp, A. K. Modular design of artificial transcription factors. Curr. Opin. Chem. Biol. 2002, 6, 765-772.

64 Pfeifer, L.; Scherübl, M.; Fellert, M.; Danowski, W.; Cheng, J.; Pol, J.; Feringa, B. L. Photoefficient 2nd generation molecular motors responsive to visible light. Chem. Sci. 2019, 10, 8768-8773. 